\title{
A Feasibility Study of a Pro-Based, Clinical Pharmacist-Led Symptom Monitoring and Management Intervention To Improve Adherence to Breast Cancer Adjuvant Endocrine Therapy
}

Joan Neuner ( $\nabla$ jneuner@mcw.edu )

Medical College of Wisconsin https://orcid.org/0000-0003-0031-5988

Elizabeth Weil

Froedtert and Medical College of Wisconsin SpineCare: SpineCare Clinics

Nicole Fergestrom

Medical College of Wisconsin

Melinda Stolley

Medical College of Wisconsin

Sailaja Kamaraju

Medical College of Wisconsin

Carolyn Oxencis

Medical College of Wisconsin

Aaron Winn

Medical College of Wisconsin

Purushottam Laud

Medical College of Wisconsin

Kathryn E. Flynn

Medical College of Wisconsin

\section{Research Article}

Keywords: breast cancer, medication adherence, patient adherence in preventive care, symptom management

Posted Date: March 18th, 2021

DOl: https://doi.org/10.21203/rs.3.rs-249542/v1

License: (9) This work is licensed under a Creative Commons Attribution 4.0 International License. Read Full License 


\section{Abstract}

Background Adjuvant endocrine therapy (AET) for breast cancer reduces mortality, but one-third to onehalf of patients discontinue it early or are nonadherent. We developed a pilot single-site study of patients with evidence of early nonadherence to AET to assess the feasibility of a novel intervention targeting symptom and medication management.

Methods: Subjects with prescription fill records showing nonadherence were enrolled in a single arm, clinical pharmacist-led, pre-post feasibility study. Automated reminders were sent by email or text with a link to symptom monitoring assessments weekly for 1 month and monthly until 6 months. Clinical oncology pharmacists used guideline-based symptom management and other medication management tools to support adherence and ameliorate symptoms reported on the assessments. Patient-reported outcome assessments included physical, mental, and social health domains, and self-efficacy to manage symptoms and medications. Feasibility outcomes included completion of symptom reports and pharmacist recommendations.

Results Of nineteen nonadherent patients who completed initial assessments, 18 completed all final study procedures, with 14 completing assessments and no patient missing $>$ three. All 18 patients reported at least one of three symptom types, and the majority reported attempting pharmacist recommendations. Patient-reported measures of physical, mental and social health, as well as selfefficacy improved, and $44 \%$ of the patients became adherent.

Conclusions: An intervention to utilize pharmacists in an oncology practice systematically monitor and manage symptoms shows promise to reduce symptoms, enhance support and self-efficacy, and improve adherence to AET.

Implications for Cancer Survivors: If future larger studies confirm these pilot findings, the intervention could improve patient symptoms and adherence.

\section{Background}

Adjuvant endocrine therapy (AET) with tamoxifen or aromatase inhibitors (Als) is the standard treatment for estrogen positive breast cancer, as it reduced recurrence and mortality in randomized trials by onequarter to one-third when taken for 5-10 years[1, 2]. Unfortunately, research now spanning a decade shows one-third to one-half of patients prescribed AET discontinue early or are nonadherent, missing a large number (often defined as $20 \%$ ) of scheduled doses [3, 4]. There are no standard alternatives to AET, and poor adherence and early discontinuation were associated with an absolute $8 \%$ reduction in 5-year overall survival in a population-based study [5]. However, addressing poor adherence has proven difficult. Of 6 recent trials in breast cancer endocrine therapy focused on education about breast cancer and its medications, some with reminders to take pills as well, none showed a statistically significant improvement in adherence [6, 7]. 
Symptoms while taking AET are important contributors to nonadherence. The symptoms most commonly associated with AET are arthralgias and other musculoskeletal symptoms, menopausal symptoms (vasomotor and genitourinary), and fatigue $[8,9,10]$. In the clinical trial setting, where medication assignment was masked and patient support by the research team was high, low adherence or early discontinuation of AET due to symptoms was rare: only $5.6 \%$ of the tamoxifen and $8.1 \%$ of the aromatase inhibitor users in the largest study discontinued because of symptoms [11]. However, systematic reviews of observational studies demonstrated the larger role that patients' symptoms play in AET persistence and adherence in the "real" world $[12,13]$. For example, in one prospective study of Al users, $32 \%$ of patients discontinued their medication, over three-quarters of them because of symptoms [14].

Several medications can improve menopausal symptoms in patients on AET, and several behavioral interventions can improve other common symptoms like fatigue and joint AET $[15,16]$. There is also evidence that switching to another one of the four available endocrine therapies can help patients tolerate symptoms $[14,15]$. Current guidelines from the American Cancer Society/American Society of Clinical Oncology and the National Comprehensive Cancer Network provide evidence-based recommendations for managing commonly reported physical and psychosocial side effects of AET [15-17].

We developed an intervention to improve adherence to AET for breast cancer by systematically monitoring and managing symptoms. We adapted methods from two types of successful interventions known to improve outcomes in other conditions. First, to maximize monitoring, we utilized frequent measurement of patient-reported symptoms. Over the last decade, methodological research has improved the measurement of symptoms through patient-reported outcomes (PROs). PROs measure a patient's perception of their well-being, including symptoms and functioning, without interpretation by a clinician. Several studies now suggest routine use of PRO measures during high-intensity treatments for cancer can better detect patient symptoms compared to physician reports $[18,19]$. For patients with metastatic solid tumors (including breast cancer), electronic self-report of common side effects at and between clinic visits, with nurse follow-up for severe symptoms, reduced emergency room visits, increased the completion rate of planned chemotherapy cycles, and improved survival over usual care by 5 months [ 18 , 20]. Second, we drew from efficacious strategies outside cancer developed using the Chronic Care Model, $[21,22]$ which redesigned the organization/practice setting to 1) identify patients not reaching goals and 2) use nonphysician providers to reach out to these patients outside of regular office visits. These efforts have been successful in improving adherence to medications across conditions including depression and hypertension [23]. In one intervention based on this approach, Kaiser California increased the percentage of their enrollees with controlled blood pressure from $45 \%$ to over $85 \%$ [24]. Finally, our intervention was designed with implementation in mind, by utilizing clinical pharmacists. Clinical pharmacists are embedded in many large oncology practices, and they are experienced with medication monitoring and counseling $[25,26]$. Herein we report the feasibility of a single-site pilot of this novel intervention. The study aimed to demonstrate the feasibility of patient identification and study procedures. We also describe the pilot participants with regard to compliance with study procedures, changes in adherence, and patient-reported outcomes. 


\section{Methods}

Study Design and Cohort. This was a single arm, clinical pharmacist-led, pre-post feasibility intervention study. We targeted patients at high risk for nonadherence or early discontinuation of AET medications rather than all patients, given many will be adherent without intervention. Since observed nonadherence is one of the few strong predictors of future nonadherence, high risk status was based on having already demonstrated nonadherence [27]. Our potentially eligible study sample pool was created using the electronic health record (EHR) to identify patients receiving AET therapy from month 9 (to allow calculation of nonadherence) through month 42 (to allow time for the intervention before therapy would be complete at 60 months). Nonadherence was defined as obtaining $<80 \%$ of all expected daily scheduled doses [28]. Nonadherence for any 6-month period in the prior 18 months was calculated based on a medication possession ratio from pharmacy refills in the Surescripts electronic all-payer, allpharmacy claims database, and was confirmed by telephone with the patient's pharmacy/ies. Other inclusion criteria included being seen by the practice's oncology practitioner(s) in the prior 18 months, having no evidence of recurrence, and having internet access to complete surveys.

Potentially eligible patients were sent an informational letter by mail/email, followed by a telephone call to describe the study, confirm eligibility, and enroll after an informed consent process. The Medical College of Wisconsin Institutional Review Board approved this study.

Symptom monitoring. We used REDCap [29] to manage patient data, including the symptom monitoring assessments underpinning the intervention as well as the PROs (described later). Participants were sent automated reminders by email or text with a link to complete symptom monitoring assessments weekly for 1 month and then monthly until 6 months. Reminders were sent each day if the assessment was not completed. After 3 reminders (3 days), a study coordinator called the participant to remind her to complete the assessment. Symptoms were assessed using 14 items from the Patient-Reported Outcomes version of the Common Terminology Criteria for Adverse Events (PRO-CTCAE ${ }^{\mathrm{TM}}$ ), a flexible system designed to capture basic information (e.g., frequency, severity) about treatment toxicities in oncology settings.[30] We randomized the order of the questions in each administration. The monitoring assessments took approximately 1.5 minutes to complete (median 1.3 minutes, range 1-5 minutes). As in previous studies, [31] the two most severe response options (e.g., a score of 3 or 4 on a 0-4 scale) or a worsening of 2 or more points triggered follow-up for management.

Symptom management. After patients completed their initial symptom report, a clinical pharmacist met with the patient to discuss results of the report, respond to questions/concerns, and make recommendations for management strategies. The pharmacist was tasked to use a summary of evidence-based interventions focused on the most common symptoms among AET users (musculoskeletal symptoms, menopausal symptoms, and fatigue) that was developed by the clinical members of the research team (JN, EW, MS, SK, CO, KF). Primary sources included three guidelines based on systematic literature reviews; [15-17] treatments supported by randomized trials published after guideline publication dates and details from trials referenced in guidelines were also used (Table 1 and 
Appendix Figure 1 for full guideline). Pharmacists' licensing in Wisconsin and 45 other states do not allow direct prescribing, but pharmacists were encouraged to provide symptom-relieving recommendations to the oncology provider team (physicians and/or advanced practice providers) for signature. The symptom management intervention was accompanied by other recommended elements of pharmacist medication management visits; [32] these elements included medication reconciliation from all available sources, confirmation of patient agreement with list, medication interaction checks, [33] reminder tool advice, and advice to the oncology team about and reducing other medications' dosing burden or cost. After each patient interaction, pharmacists recorded time spent with the patient and the content discussed within the EHR. Safety procedures were in place for symptoms suggesting an acute problem, including pathways for referral to mental health providers.

After the initial visit, a pharmacist followed up with patients to ensure that they were able to follow through on any initial management recommendations (e.g., has information about yoga studio, prescription picked up), and then again to follow-up on the impact of the recommendation on the patients symptoms. The timing and communication method of these follow-ups varied depending on patient needs. If required, additional recommendations were made to palliate symptoms.

For the duration of the 6-month study, any new severe symptoms reported by patients in response to prompted symptom monitoring were sent to the pharmacy team with a copy to the oncologist. Clinical pharmacists then conducted additional management phone calls with patients in the same way as described above.

\section{Pharmacist training}

To mimic current care practices and enhance future dissemination, decisions including whether the visit should be in-person or telephone, and the tailoring of the visit elements were based on patient preference and pharmacist judgment. However, to ensure similar practices across pharmacists, all members of the clinical pharmacy team received a sixty-minute training session (Table 1). The session focused on side effect amelioration using the guideline summary developed by the investigator team, other medication management elements, and teaching around interpretation of PRO results.

\section{Intervention refinement}

\section{Outcome assessments}

We collected comprehensive PRO assessments at baseline, 3, and 6 months that covered a broad set of physical, mental, and social health domains, as well as self-efficacy to manage symptoms and selfefficacy to manage medications (domains listed in Table 4). We used Patient-Reported Outcome Measurement Information System (PROMIS) computerized adaptive tests through REDCap for the outcome assessments. PROMIS is the NIH's initiative to standardize measurement of PROs in clinical research across all chronic conditions [34]. PROMIS measures have a U.S. population mean of 50 with SD of 10 , and differences/changes of $>3$ points is typically considered meaningful. We describe baseline 
PRO scores in comparison to US and SEER reference populations as well as changes in PRO scores over time. We also assessed end-of study adherence, calculating it as obtaining $<80 \%$ of all expected daily scheduled doses [28] for the 6-month period. As for enrollment, adherence was calculated based on a medication possession ratio from pharmacy refills in the Surescripts electronic all-payer, all-pharmacy claims database, and was confirmed by telephone with the patient's pharmacy/ies.

\section{Results}

Participants Of 38 eligible patients contacted from 1 of 3 local clinics, 18 declined participation and 20 consented and enrolled in the study, representing a 47\% enrollment rate. Of 20 consented patients, 19 completed baseline assessment and 18 completed the initial pharmacist consultation intervention. Those 18 participants were on average 56 years of age (SD 9.1) and their baseline adherence was $61.0 \%$ (SD 16\%) (Table 2). The majority had been diagnosed with stage I cancer, $45 \%$ were taking an $\mathrm{Al}, 22 \%$ tamoxifen, and $33 \%$ had self-discontinued their medication. Nine of 18 had already tried at least one medication switch among the four medications ( $28 \%$ one switch and $22 \%$ more than one).

\section{Symptom Reports Completion, Results and Pharmacist-led Intervention}

During the initial month of weekly symptom monitoring and the monthly monitoring that followed, 14 of 18 patients completed all expected PRO assessments, 3 missed 1-2 assessments and 1 missed three assessments. All 18 patients reported at least one of four symptom types (musculoskeletal, vasomotor and urogenital, fatigue) during the six-month study period, with 3 reporting only one, 7 reporting two and 8 reporting all three.

Pharmacist discussions and interventions made with oncology providers were analyzed specific to the three symptom types. An intervention pharmacist discussed symptoms with 14 of the 17 patients who reported musculoskeletal symptoms ( 2 could not be reached, 1 declined discussion). Of those 14,7 had underlying diagnoses the pharmacist believed explained the symptoms at least in part (e.g., osteoarthritis). The pharmacist gave one or more guideline-based recommendations (e.g., exercise, acupuncture) for 12 patients. Six patients with symptoms were counseled to consider a switch from one Al to another, and two did this. Over $50 \%$ of patients reported attempting each of the recommendations, with the exception of acupuncture which no patients attempted (Table 3). A pharmacist discussed symptoms with 13 of the 14 patients who reported vasomotor symptoms, and all 10 were given guidelinebased prescriptions or recommendations. Over $50 \%$ of patients reported attempting each of the recommendations, again with the exception of acupuncture which no patients attempted. A pharmacist discussed urogenital symptoms with all eight patients reporting symptoms, and six were given guidelinebased recommendations. Over $50 \%$ of patients reported attempting each of these prescribed/recommended treatments for urogenital symptoms. Results for fatigue were similar to those for urogenital symptoms

\section{Pharmacist Time and Acceptability}


The pharmacists completed 65 total encounters (all telephone calls) for a total of 26.4 hours of pharmacist time. Every patient received at least one (baseline) call. The mean number of calls was 3.61(S.D. 2.26), with only 2 patients receiving the minimum one baseline call, and one patient receiving 10 calls. Mean pharmacist time for the total of all completed calls per patient was 88.1 minutes (S.D. 55.3) over the 6-month study. In addition, there were 70 unanswered call attempts.

The intervention was also acceptable to clinical pharmacists. In exit interviews with all participating pharmacists $(n=5)$, they reported enjoying the opportunity to participate in patient care during the survivorship phase. They perceived they were able to successfully use the PRO scores to guide conversations and offer guideline-concordant management of symptoms. They also identified ways to improve the intervention with regard to workflow and documentation, as described above (Intervention refinement).

\section{Adherence}

Per eligibility criteria, all patients included in the study were nonadherent (6-month medication possession ratio $<80 \%$ ) at baseline as calculated from pharmacy fills. During the six-month study period, $44 \%$ of patients $(n=8)$, again calculated from pharmacy fills, were adherent.

\section{Patient-reported outcomes}

Baseline PROMIS scores indicated that compared to the US general population, pilot participants had worse self-efficacy, physical functioning, pain, fatigue, and sleep (Table 4). Compared to the US general population, pilot participants had similar social functioning, anxiety, and depression, as well as better social support (Table 4). Pilot participants were similar to US women with any stage breast cancer, though pilot participants reported worse anxiety. Scores improved over time in all domains with $>3$ point improvements at 3 months in self-efficacy to manage symptoms, social function, informational support, pain, fatigue, and anxiety. By 6 months, there were $>3$ point improvements in all domains except emotional support and depression, while scores on informational support actually decreased a small amount. The largest improvements were in ability to participate in social roles and activities (5.5 points), instrumental support (5.8 points), pain (7.1 points), fatigue (6 points), and sleep-related impairment (6.5 points).

\section{Discussion}

This pilot study was conducted to assess feasibility of a symptom monitoring and management intervention facilitated by clinical pharmacists to improve persistence with AET. We were successful in identifying patients through the EHR using an embedded electronic all-payer, all-pharmacy claims database. We also demonstrated that patients were willing to enroll in this type of study and comply with symptom monitoring and management. Because of small sample size, we did not include any statistical evaluation of adherence or patient-reported outcomes including self-efficacy to manage symptoms and medications, however both outcome categories showed clinically significant improvements. 
We were able to efficiently identify and recruit a high-risk patient population for this feasibility study. We used electronic all-payer, all-pharmacy claims data already available in our electronic health record to enroll patients with evidence of prior nonadherence (i.e., skipping medication doses based on prescription fills over the prior nine-month period). We targeted this group because prior reviewers of adherence literature have advocated identifying higher risk groups to improve study efficiency, and nonadherence is one of the few strong predictors of future nonadherence [27]. Future studies should examine both the efficacy of our approach in a large targeted population. and the population-wide adherence effects of targeted studies.

Consistent with our expectations based on prior literature,[12,13] our study sample was very symptomatic. The PRO-based symptom monitoring process worked well for measuring this and providing the information to the pharmacists. Patients successfully completed nearly all of the symptom assessments, which took most patients less than 2 minutes to complete on a computer or smartphone. To make the intervention more accessible, we suggest that future iterations accommodate symptom assessment by telephone through an interactive voice recording (IVR) system, as has been done in other symptom monitoring and management interventions [35].

We designed the intervention to include substantial time with medical professionals (clinical pharmacists) with extensive training and experience regarding oncologic medications. Patient symptom burden was high, and the time patients and pharmacists spent on study visits was substantial, averaging 88 minutes per patient. However, the use of pharmacists is less expensive than an intervention involving oncologists. We also believe targeting pharmacists maximizes the sustainability and potential for dissemination. Pharmacists in many large academic practices already perform medication management visits for complex and costly oral (or oral and intravenous combination) oncologic regimens such as those for metastatic breast and lung cancer[25,26]. If the intervention is shown to be effective in a larger and longer-term study, these clinical pharmacists could add PRO-enhanced AET management to their work and improve outcomes for a large patient group.

We also note that study participants were willing to try many of the recommendations from pharmacists. For many patients, these included behavioral modifications to address musculoskeletal symptoms, which some literature suggests is the primary reason for Al discontinuation [14]. This was accompanied by improvements in average symptom scores, including pain interference and fatigue, and an improvement in average physical function scores. Furthermore, while we could not formally test the statistical significance of our finding that $44 \%$ of previously nonadherent patients became adherent, prior literature suggests this is unlikely to be due to chance [36].

This was a small, single-site pre-post pilot study with a relatively short follow-up period. This is appropriate for a feasibility study, but a larger randomized study with longer follow-up is needed to determine both efficacy and costs. Even with its pharmacist-focused design, we recognize that our intervention might be more time-consuming and complex for on-site personnel than a simpler intervention. Many simpler past interventions outside of oncology have focused primarily on providing 
reminders at the time medications should be taken, education on the importance of medications, or both. We designed our more complex intervention because such interventions, including more recent ones that incorporated "just-in time" reminders (electronic pill bottles with alerts, mobile telephone alerts), produce improvements in adherence of only $5-10 \%[37,38,39]$. Future studies could consider comparisons of our more extensive intervention to a reminder and education-focused intervention. Another potential limitation was the use of PRO-CTCAE items, which were designed for evaluating toxicities in trials and not necessarily for use in a clinical care setting. That said, the items lend themselves well for this purpose, with straightforward questions about individual symptoms and uncomplicated scoring. We chose these items as they are similar to the ones used in other PRO-based symptom monitoring and management studies $[18,20]$. We expect that other PRO measures with similar properties would likewise work in this context. Because use of the Surescripts information was new, we used an iterative process to identify potentially eligible patients, so total eligible population could not be determined. Finally, because our intervention was developed by a team including an oncologist and pharmacist, we believe there was substantial informal training of the entire pharmacy and oncology team. We expect to expand our onehour training session in a future multicenter study, and also provide information about the training to oncology providers.

In summary, this pilot study showed the feasibility of a novel intervention, a PRO-based symptom monitoring and pharmacist-led symptom management approach. The intervention draws on chronic care tools commonly used in primary care and successful PRO-based interventions to manage side effects of cytotoxic chemotherapy. The improvements in measures of patient self-efficacy suggest possible mechanisms for the intervention and should be studied further in a randomized setting. Oncology research has typically been focused on shorter-term treatments.[40] As an increasing number of longerterm, oral treatments are approved in oncology, systems for providing chronic care need to be tested and adopted. Both adherence and the PROs in this pilot moved in the right direction, supporting the need for a larger, powered study that can test the effect of the intervention on adherence and PROs.

\section{Declarations}

Funding: This study was supported by the Medical College of Wisconsin Cancer Center.

Conflicts of Interest: The authors have no relevant financial or non-financial interests to disclose.

\section{Availability of data and material: Not applicable}

Code availability: Not applicable

Ethics approval: This study was approved by the Medical College of Wisconsin/Froedtert Hospital Institutional Review Board and was performed in line with the principles of the Declaration of Helsinki.

Consent to participate: Verbal informed consent was obtained prior to participating in this study.

Consent for publication: Verbal informed consent was obtained prior to participating in this study. 


\section{References}

1. Early Breast Cancer Trialists' Collaborative Group. Aromatase inhibitors versus tamoxifen in early breast cancer: patient-level meta-analysis of the randomised trials. Lancet. 2015;386:1341-52. https://doi.org/10.1016/S0140-6736(15)61074-1

2. Goss PE, Ingle JN, Pritchard KI, Robert NJ, Muss H, Gralow J, Gelmon K, Whelan T, Strasser-Weippl K, Rubin S, Sturtz K, Wolff AC, Winer E, Hudis C, Stopeck A, Beck JT, Kaur JS, Whelan K, Tu D and Parulekar WR. Extending aromatase-inhibitor adjuvant therapy to 10 years. N Engl J Med. 2016;375:209-19. DOI: 10.1056/NEJMoa1604700

3. Partridge AH, Wang PS, Winer EP and Avorn J. Nonadherence to adjuvant tamoxifen therapy in women with primary breast cancer. J Clin Oncol. 2003;21:602-606. DOI: 10.1200/JC0.2003.07.071

4. Murphy CC, Bartholomew LK, Carpentier MY, Bluethmann SM and Vernon SW. Adherence to adjuvant hormonal therapy among breast cancer survivors in clinical practice: a systematic review. Breast Cancer Res Treat. 2012;134:459-78. https://doi.org/10.1007/s10549-012-2114-5

5. Hershman DL, Shao T, Kushi LH, Buono D, Tsai WY, Fehrenbacher L, Kwan M, Gomez SL and Neugut Al. Early discontinuation and non-adherence to adjuvant hormonal therapy are associated with increased mortality in women with breast cancer. Breast Cancer Res Treat. 2011;126:529-537. https://doi.org/10.1007/s10549-010-1132-4

6. Hurtado-de-Mendoza A, Cabling ML, Lobo T, Dash C and Sheppard VB. Behavioral Interventions to Enhance Adherence to Hormone Therapy in Breast Cancer Survivors: A Systematic Literature Review. Clin Breast Cancer. 2016;16:247-255 e3. https://doi.org/10.1016/j.clbc.2016.03.006

7. Hershman DL, Unger JM, Hillyer GC, Moseley A, Arnold KB, Dakhil SR, Esparaz BT, Kuan MC, II MLG, Lackowski DM, Edenfield WJ, Dayao ZR, Henry NL, Gralow JR, Ramsey SD and Neugut Al. Randomized Trial of Text Messaging to Reduce Early Discontinuation of Adjuvant Aromatase Inhibitor Therapy in Women With Early-Stage Breast Cancer: SWOG S1105. Journal of Clinical Oncology. 2020;38:2122-2129. DOI: 10.1200/JC0.19.02699

8. Baum M, Budzar AU, Cuzick J, Forbes J, Houghton JH, Klijn JG, Sahmoud T, Group AT, Baum M, Budzar AU, Cuzick J, Forbes J, Houghton JH, Klijn JGM, Sahmoud T and Group AT. Anastrozole alone or in combination with tamoxifen versus tamoxifen alone for adjuvant treatment of postmenopausal women with early breast cancer: first results of the ATAC randomised trial. Lancet. 2002;359:2131-9. https://doi.org/10.1016/S0140-6736(02)09088-8

9. Coates AS, Keshaviah A, Thurlimann B, Mouridsen H, Mauriac L, Forbes JF, Paridaens R, CastiglioneGertsch M, Gelber RD, Colleoni M, Lang I, Del Mastro L, Smith I, Chirgwin J, Nogaret JM, Pienkowski T, Wardley A, Jakobsen EH, Price KN and Goldhirsch A. Five years of letrozole compared with tamoxifen as initial adjuvant therapy for postmenopausal women with endocrine-responsive early breast cancer: update of study BIG 1-98.[see comment]. Journal of Clinical Oncology. 2007;25:486-92. DOI: $10.1200 / J C 0.2006 .08 .8617$

10. Coombes RC, Kilburn LS, Snowdon CF, Paridaens R, Coleman RE, Jones SE, Jassem J, Van de Velde CJ, Delozier T, Alvarez I, Del Mastro L, Ortmann O, Diedrich K, Coates AS, Bajetta E, Holmberg SB, 
Dodwell D, Mickiewicz E, Andersen J, Lonning PE, Cocconi G, Forbes J, Castiglione M, Stuart N, Stewart A, Fallowfield LJ, Bertelli G, Hall E, Bogle RG, Carpentieri M, Colajori E, Subar M, Ireland E, Bliss JM and Intergroup Exemestane S. Survival and safety of exemestane versus tamoxifen after 23 years' tamoxifen treatment (Intergroup Exemestane Study): a randomised controlled trial. Lancet. 2007;369:559-70. https://doi.org/10.1016/S0140-6736(07)60200-1

11. Arimidex TAoiCTG, Buzdar A, Howell A, Cuzick J, Wale C, Distler W, Hoctin-Boes G, Houghton J, Locker GY and Nabholtz JM. Comprehensive side-effect profile of anastrozole and tamoxifen as adjuvant treatment for early-stage breast cancer: long-term safety analysis of the ATAC trial. Lancet Oncol. 2006;7:633-43. https://doi.org/10.1016/S1470-2045(06)70767-7

12. Kidwell KM, Harte SE, Hayes DF, Storniolo AM, Carpenter J, Flockhart DA, Stearns V, Clauw DJ, Williams DA and Henry NL. Patient-reported symptoms and discontinuation of adjuvant aromatase inhibitor therapy. Cancer. 2014;120:2403-11. https://doi.org/10.1002/cncr.28756

13. Cahir C, Guinan E, Dombrowski SU, Sharp L and Bennett K. Identifying the determinants of adjuvant hormonal therapy medication taking behaviour in women with stages IIII breast cancer: A systematic review and meta-analysis. Patient Educ Couns. 2015. https://doi.org/10.1016/j.pec.2015.05.013

14. Henry NL, Azzouz F, Desta Z, Li L, Nguyen AT, Lemler S, Hayden J, Tarpinian K, Yakim E, Flockhart DA, Stearns $V$, Hayes DF and Storniolo AM. Predictors of Aromatase Inhibitor Discontinuation as a Result of Treatment-Emergent Symptoms in Early-Stage Breast Cancer. Journal of Clinical Oncology. 2012;30:936-942. doi: 10.1200/JC0.2011.38.0261

15. Runowicz CD, Leach CR, Henry NL, Henry KS, Mackey HT, Cowens-Alvarado RL, Cannady RS, PrattChapman ML, Edge SB, Jacobs LA, Hurria A, Marks LB, LaMonte SJ, Warner E, Lyman GH and Ganz PA. American Cancer Society/American Society of Clinical Oncology Breast Cancer Survivorship Care Guideline. J Clin Oncol. 2016;34:611-35. https://doi.org/10.3322/caac.21319

16. Gradishar WJ, Anderson BO, Balassanian R and al. E. NCCN Clinical Practice Guidelines in Oncology: Breast Cancer Version 3, 2017.

17. Carter J, Lacchetti C, Andersen BL, Barton DL, Bolte S, Damast S, Diefenbach MA, DuHamel K, Florendo J, Ganz PA, Goldfarb S, Hallmeyer S, Kushner DM and Rowland JH. Interventions to Address Sexual Problems in People With Cancer: American Society of Clinical Oncology Clinical Practice Guideline Adaptation of Cancer Care Ontario Guideline. J Clin Oncol. 2018;36:492-511. : https://doi.org/10.1200/JC0.2017. 75.8995

18. Basch E, Deal AM, Kris MG, Scher HI, Hudis CA, Sabbatini P, Rogak L, Bennett AV, Dueck AC, Atkinson TM, Chou JF, Dulko D, Sit L, Barz A, Novotny P, Fruscione M, Sloan JA and Schrag D. Symptom Monitoring With Patient-Reported Outcomes During Routine Cancer Treatment: A Randomized Controlled Trial. J Clin Oncol. 2016;34:557-65. doi: 10.1200/JC0.2015.63.0830

19. Berry DL, Blumenstein BA, Halpenny B, Wolpin S, Fann JR, Austin-Seymour M, Bush N, Karras BT, Lober WB and McCorkle R. Enhancing patient-provider communication with the electronic self-report assessment for cancer: a randomized trial. J Clin Oncol. 2011;29:1029-35.

doi: $10.1200 / J C 0.2010 .30 .3909$

Page $11 / 18$ 
20. Basch E, Deal AM, Dueck AC and et al. Overall survival results of a trial assessing patient-reported outcomes for symptom monitoring during routine cancer treatment. JAMA. 2017;318:197-198.

21. Bodenheimer $\mathrm{T}$, Wagner $\mathrm{EH}$ and Grumbach $\mathrm{K}$. Improving primary care for patients with chronic illness. JAMA. 2002;288:1775-9. doi:10.1001/jama.2017.7156

22. Halladay JR, DeWalt DA, Wise A, Qaqish B, Reiter K, Lee SY, Lefebvre A, Ward K, Mitchell CM and Donahue KE. More extensive implementation of the chronic care model is associated with better lipid control in diabetes. J Am Board Fam Med. 2014;27:34-41. DOI:

https://doi.org/10.3122/jabfm.2014.01.130070

23. Katon WJ, Lin EH, Von Korff M, Ciechanowski P, Ludman EJ, Young B, Peterson D, Rutter CM, McGregor M and McCulloch D. Collaborative care for patients with depression and chronic illnesses. N Engl J Med. 2010;363:2611-20. DOI: 10.1056/NEJMoa1003955

24. Jaffe MG, Lee GA, Young JD, Sidney $S$ and Go AS. Improved blood pressure control associated with a large-scale hypertension program. JAMA. 2013;310:699-705. doi:10.1001/jama.2013.108769

25. Valgus J, Jarr S, Schwartz R, Rice M and Bernard SA. Pharmacist-Led, Interdisciplinary Model for Delivery of Supportive Care in the Ambulatory Cancer Clinic Setting. Journal of Oncology Practice. 2010;6:e1-e4. DOI: 10.1200/JOP.2010.000033

26. Khrystolubova N, Shieh M, Patel AJ and Bailey R. Pharmacist-led patient education and adverse event management in patients with non-small cell lung cancer receiving afatinib in a communitybased, real-world clinical setting. J Oncol Pharm Pract. 2020;26:13-22.

27. Franklin JM, Shrank WH, Lii J, Krumme AK, Matlin OS, Brennan TA and Choudhry NK. Observing versus Predicting: Initial Patterns of Filling Predict Long-Term Adherence More Accurately Than HighDimensional Modeling Techniques. Health Serv Res. 2016;51:220-39. https://doi.org/10.1111/14756773.12310

28. Raebel MA, Schmittdiel J, Karter AJ, Konieczny JL and Steiner JF. Standardizing Terminology and Definitions of Medication Adherence and Persistence in Research Employing Electronic Databases. Medical Care. 2013;51:S11-S21. doi: 10.1097/MLR.0b013e31829b1d2a

29. Harris PA, Taylor R, Thielke R, Payne J, Gonzalez N and Conde JG. Research electronic data capture (REDCap)-a metadata-driven methodology and workflow process for providing translational research informatics support. J Biomed Inform. 2009;42:377-81. https://doi.org/10.1016/j.jbi.2008.08.010

30. Dueck AC, Mendoza TR, Mitchell SA, Reeve BB, Castro KM, Rogak LJ, Atkinson TM, Bennett AV, Denicoff AM, O'Mara AM, Li Y, Clauser SB, Bryant DM, Bearden JD, 3rd, Gillis TA, Harness JK, Siegel RD, Paul DB, Cleeland CS, Schrag D, Sloan JA, Abernethy AP, Bruner DW, Minasian LM, Basch E and National Cancer Institute PROCSG. Validity and Reliability of the US National Cancer Institute's Patient-Reported Outcomes Version of the Common Terminology Criteria for Adverse Events (PROCTCAE). JAMA Oncol. 2015;1:1051-9. doi:10.1001/jamaoncol.2015.2639

31. Basch E, Deal AM, Kris MG, Scher HI, Hudis CA, Sabbatini P, Rogak L, Bennett AV, Dueck AC, Atkinson TM, Chou JF, Dulko D, Sit L, Barz A, Novotny P, Fruscione M, Sloan JA and Schrag D. Symptom 
Monitoring With Patient-Reported Outcomes During Routine Cancer Treatment: A Randomized Controlled Trial. Journal of Clinical Oncology. 2016;34:557-565. doi: 10.1200/JC0.2015.63.0830

32. https://www.medicare.gov/drug-coverage-part-d/what-medicare-part-d-drug-plans-cover/medicationtherapy-management-programs-for-complex-health-needs. Accessed February 4, 2021.

33. Del Re M, Citi V, Crucitta S, Rofi E, Belcari F, van Schaik RH and Danesi R. Pharmacogenetics of CYP2D6 and tamoxifen therapy: Light at the end of the tunnel? Pharmacological Research. 2016;107:398-406. https://doi.org/10.1016/j.phrs.2016.03.025

34. Cella D, Riley, W., Stone, A., Rothrock, N., Reeve, B., Yount, S., Amtmann, D., Bode, R., Buysse, D., Choi, S., Cook, K., DeVellis, R., DeWalt, D., Fries, J. F., Gershon, R., Hahn, E. A., Pilkonis, P., Revicki, D., Rose, M., Weinfurt, K., Hays, R., Lai, J-S. The Patient Reported Outcomes Measurement Information System (PROMIS) developed and tested its first wave of adult self-reported health outcome item banks: 2005-2008 Journal of Clinical Epidemiology. 2010;63:1179-1194.

https://doi.org/10.1016/j.jclinepi.2010.04.011

35. Bennett AV, Dueck AC, Mitchell SA, Mendoza TR, Reeve BB, Atkinson TM, Castro KM, Denicoff A, Rogak LJ, Harness JK, Bearden JD, Bryant D, Siegel RD, Schrag D, Basch E and National Cancer Institute PROCSG. Mode equivalence and acceptability of tablet computer-, interactive voice response system-, and paper-based administration of the U.S. National Cancer Institute's PatientReported Outcomes version of the Common Terminology Criteria for Adverse Events (PRO-CTCAE). Health and quality of life outcomes. 2016;14:24. https://doi.org/10.1186/s12955-016-0426-6

36. Winn AN, Fergestrom NM and Neuner JM. Using Group-based Trajectory Models and Propensity Score Weighting to Detect Heterogeneous Treatment Effects: The Case Study of Generic Hormonal Therapy for Women With Breast Cancer. Med Care. 2019;57:85-93. doi: 10.1097/MLR.0000000000001019

37. Nieuwlaat R, Wilczynski N, Navarro T, Hobson N, Jeffery R, Keepanasseril A, Agoritsas T, Mistry N, Iorio A, Jack S, Sivaramalingam B, Iserman E, Mustafa RA, Jedraszewski D, Cotoi C and Haynes RB. Interventions for enhancing medication adherence. Cochrane Database of Systematic Reviews. 2014. https://doi.org/10.1002/14651858.CD000011.pub4

38. Choudhry NK, Krumme AA, Ercole PM, Girdish C, Tong AY, Khan NF, Brennan TA, Matlin OS, Shrank WH and Franklin JM. Effect of Reminder Devices on Medication Adherence: The REMIND Randomized Clinical Trial. JAMA Intern Med. 2017;177:624 631. doi:10.1001/jamainternmed.2016.9627

39. Volpp KG, Troxel AB, Mehta SJ, Norton L, Zhu J, Lim R, Wang W, Marcus N, Terwiesch C, Caldarella K, Levin T, Relish M, Negin N, Smith-McLallen A, Snyder R, Spettell CM, Drachman B, Kolansky D and Asch DA. Effect of Electronic Reminders, Financial Incentives, and Social Support on Outcomes After Myocardial Infarction: The HeartStrong Randomized Clinical Trial. JAMA Intern Med. 2017;177:10931101. doi:10.1001/jamainternmed.2017.2449

40. Taplin SH, Anhang Price R, Edwards HM, Foster MK, Breslau ES, Chollette V, Prabhu Das I, Clauser SB, Fennell ML and Zapka J. Introduction: Understanding and Influencing Multilevel Factors Across the 
Cancer Care Continuum. JNCI Monographs. 2012;2012:2-10.

https://doi.org/10.1093/jncimonographs/lgs008

\section{Tables}

Table 1. Elements of Intervention

\section{Symptom Monitoring}

Musculoskeletal 2 items on aching muscles and aching joints

Menopausal 5 items on hot flashes, sweating, vaginal dryness, dyspareunia, and urinary incontinence

Fatigue $\quad 1$ item on fatigue or lack of energy

Mental health $\quad 1$ item on anxiety, 2 items on depressive symptoms

Other $\quad 3$ items on nausea, headache, and concentration

\section{Symptom Management}

Non-adherence Patient's PDC from pharmacy information; anything below $80 \%$ is non-adherent, e.g., a value of $60 \%$ shows that patient picked up $60 \%$ of expected medication doses over the last 9 months. ${ }^{28}$

Interpretation of PRO reports

Guidelineconcordant symptom management
Any score of 3 or 4 on 0-4 scale will trigger team follow-up for management. ${ }^{31}$

Consensus statements and reviews of evidence-based interventions for symptoms, ${ }^{15,16}$ with procedures for high-risk scenarios. Specific recommendations available for joint pain: exercise, acupuncture; for menopausal symptoms: gabapentin, SNRIs; for fatigue: exercise. Endocrine therapy switching option also available.

Other elements of medication management visits agreement with list, reminder tools, interaction check, ${ }^{33}$ interventions to reduce other medications' dosing burden/cost.
Medication reconciliation from all available sources, confirmation of patient

Table 2. Patient characteristics $(n=18)$ 


\begin{tabular}{|c|c|c|}
\hline Characteristic & $\mathbf{N}$ & $\%$ * \\
\hline \multicolumn{3}{|l|}{ Age } \\
\hline Years (Mean, SD) & \multicolumn{2}{|c|}{$56.0(9.1)$} \\
\hline \multicolumn{3}{|l|}{ Race } \\
\hline Black or African American & 2 & 11 \\
\hline White & 16 & 89 \\
\hline \multicolumn{3}{|l|}{ Ethnicity } \\
\hline Hispanic & 1 & 5 \\
\hline Not Hispanic & 17 & 95 \\
\hline \multicolumn{3}{|l|}{ Marital Status } \\
\hline Married & 15 & 83 \\
\hline Single & 1 & 6 \\
\hline Divorced & 1 & 6 \\
\hline Widowed & 1 & 6 \\
\hline \multicolumn{3}{|l|}{ Stage at diagnosis } \\
\hline 1 & 14 & 78 \\
\hline II & 3 & 17 \\
\hline III & 1 & 5 \\
\hline \multicolumn{3}{|l|}{ Medication on enrollment } \\
\hline Anastrozole & 3 & 17 \\
\hline Exemestane & 1 & 6 \\
\hline Letrozole & 4 & 22 \\
\hline Tamoxifen & 4 & 22 \\
\hline None (self-discontinued medication) & 6 & 33 \\
\hline \multicolumn{3}{|l|}{ Symptoms Reported, by Type } \\
\hline Musculoskeletal & 17 & 94 \\
\hline \multicolumn{3}{|l|}{ Menopausal } \\
\hline Vasomotor & 14 & 78 \\
\hline Urogenital & 8 & 44 \\
\hline
\end{tabular}


*Totals may not equal 100 because of rounding

Table 3. Management of Musculoskeletal Symptoms 


\section{Symptom reports}

$>2$ reported

Clinical pharmacist discussed with patient

Underlying Condition

7

Unable to reach after severe score

2

\section{Symptom Management recommendations}

Exercise

Acupuncture

8

Non-Narcotic pain medications

1

Switch AET medication

6

Additional intervention recommended

5

\section{Patient agreed to recommendation}

Exercise

8

Acupuncture

4

Non-Narcotic pain medications

0

Switch AET medication

Additional Intervention Plan Agreed

4

\section{Patient reported attempting recommendation}

Exercise

5

Acupuncture

0

Non-Narcotic pain medication

0

Switch AET medication

2

Additional Intervention Attempted

4

Unable to connect with patient to confirm patient attempted recommendation

4

Table 4. Patient-reported outcome mean scores at baseline and over time 


\begin{tabular}{|c|c|c|c|c|c|}
\hline PROMIS Domain & $\begin{array}{l}\text { U.S. General } \\
\text { Population }{ }^{1}\end{array}$ & $\begin{array}{l}\text { U.S. Women with } \\
\text { Breast Cancer }{ }^{2} \\
(n=609)\end{array}$ & $\begin{array}{l}\text { Pilot } \\
\text { Baseline } \\
(n=16)\end{array}$ & $\begin{array}{l}\text { Pilot } \\
3 \\
\text { months } \\
(n=16)\end{array}$ & $\begin{array}{l}\text { Pilot } \\
6 \\
\text { months } \\
(n=16)\end{array}$ \\
\hline \multicolumn{6}{|c|}{ Functioning (higher scores represent better functioning) } \\
\hline $\begin{array}{l}\text { Self-efficacy to Manage } \\
\text { Medications }\end{array}$ & 50 & - & 46.3 & 48.5 & 50.7 \\
\hline $\begin{array}{l}\text { Self-efficacy to Manage } \\
\text { Symptoms }\end{array}$ & 50 & - & 47.2 & 51.6 & 51.9 \\
\hline Physical Function & 50 & 44.9 & 46.7 & 48.5 & 51.0 \\
\hline $\begin{array}{l}\text { Ability to Participate in } \\
\text { Social Roles and Activities }\end{array}$ & 50 & 50.7 & 51.2 & 54.8 & 56.7 \\
\hline Emotional Support & 50 & - & 53.4 & 55.3 & 55.4 \\
\hline Instrumental Support & 50 & - & 55.8 & 58.0 & 61.6 \\
\hline Informational Support & 50 & - & 55.3 & 59.4 & 57.5 \\
\hline \multicolumn{6}{|c|}{ Symptoms (higher scores represent worse symptoms) } \\
\hline Pain Interference & 50 & 52.8 & 55.2 & 50.1 & 48.1 \\
\hline Fatigue & 50 & 52.5 & 55.9 & 51.4 & 49.9 \\
\hline Depression & 50 & 48.5 & 50.5 & 47.7 & 47.7 \\
\hline Anxiety & 50 & 49.6 & 52.8 & 48.4 & 48.5 \\
\hline Sleep Disturbance & 50 & 51.7 & 53.3 & 51.9 & 50.3 \\
\hline Sleep-Related Impairment & 50 & - & 54.3 & 53.4 & 47.8 \\
\hline
\end{tabular}

${ }^{1}$ A PROMIS score of 50 and SD of 10 corresponds to the US general population average (men and women).

${ }^{2}$ Sample from 4 SEER cancer registries, diagnosed 6-13 months previously. Averages for Stage I are better than for Stage II, which are better than for Stages III and IV.

\section{Supplementary Files}

This is a list of supplementary files associated with this preprint. Click to download.

- AppendixFigurePharmacistalgorithmrecommendations.docx 